\title{
Dezocine prevents sufentanil-induced respiratory depression during awake intubation: a multicenter, randomized, controlled study
}

\section{Xiao Pan}

First Affiliated Hospital of Anhui Medical University

\section{Hongyun Zou}

The First Affiliated Hospital of Anhui Medical University

Rui Li

Second Affiliated Hospital of Anhui Medical University

\section{Shujiang Xia}

the Chaohu Hospital of Anhui Medical University

Xia Ju

the Anqing Hospital of Anhui Medical University

\section{Qi Zhang}

the Second People's Hospital of Wuhu

\section{Guanghong Xu}

First Affiliated Hospital of Anhui Medical University

\section{Xinqi Cheng}

First Affiliated Hospital of Anhui Medical University

\section{Erwei Gu}

First Affiliated Hospital of Anhui Medical University

Xuesheng Liu ( $\square$ liu711029@hotmail.com)

First Affiliated Hospital of Anhui Medical University https://orcid.org/0000-0003-3779-2964

\section{Research Article}

Keywords: Awake intubation, Sufentanil, Dezocine, Respiratory depression

Posted Date: March 3rd, 2021

DOI: https://doi.org/10.21203/rs.3.rs-279391/v1

License: () (i) This work is licensed under a Creative Commons Attribution 4.0 International License. Read Full License 


\section{Abstract}

Background

Sufentanil has sedative and inhibitory effects on the intubation response, but high doses of sufentanil can cause coughing and respiratory depression. Dezocine has been documented effectively suppressing sufentanil-induced cough. Whether dezocine can inhibit the respiratory depression caused by sufentanil is unknown. This study aims to observe the efficacy of dezocine combined with sufentanil in awake intubation.

Methods

Four hundred and three patients of American Society of Anesthesiologists physical status Classes I and II, aged 18-65 years, were randomly allocated into four groups: Group saline (saline + $0.4 \mathrm{ug} / \mathrm{kg}$ sufentanil), Group D0.05 (dezocine $0.05 \mathrm{mg} / \mathrm{kg}+0.4 \mathrm{ug} / \mathrm{kg}$ sufentanil), Group D0.10 (dezocine $0.10 \mathrm{mg} / \mathrm{kg}+0.4 \mathrm{ug} / \mathrm{kg}$ sufentanil), and Group D0.15 (dezocine $0.15 \mathrm{mg} / \mathrm{kg}+0.4 \mathrm{ug} / \mathrm{kg}$ sufentanil). The primary outcome of our study was to observe the incidence of respiratory depression. Secondary outcomes included the success rate of intubation, ease of intubation, intubation comfort score, sore throat, hoarseness, lethargy, limb movement, glottis exposing and the satisfaction of patients during intubation. Hemodynamic changes were recorded after sufentanil injection and awake intubation.

Results

There was no difference in the effect of normal saline and $0.05 \mathrm{mg} / \mathrm{kg}$ dezocine on respiratory depression $(P=0.603)$. The incidence of respiratory depression in Group D0.10 and Group D0.15 was lower than that of Group saline. Cough was statistically different between the four groups $(P<0.05)$. The incidence of cough in the dezocine groups was lower than that of Group saline. There was a significant difference in patient intubation satisfaction between the four groups $(P<0.05)$. The satisfaction of patients during intubation were significantly higher in the dezocine groups. Sore throat, hoarseness, lethargy and success rate of intubation were similar between the four groups (all $P>0.05$ ).

Conclusions

Our study indicated that $0.10 \mathrm{mg} / \mathrm{kg}$ and $0.15 \mathrm{mg} / \mathrm{kg}$ dezocine might prevent the occurrence of cough and respiratory depression induced by sufentanil during awake intubation and improve patient satisfaction.

Trial registration

Clinicaltrials.gov (NCT02673723), 2- 4- 2016.

\section{Introduction}

Anesthesia safety has greatly improved in the last half century. However, the incidence of difficult airway in patients undergoing endotracheal intubation is still between $1 \%$ and $18 \%$ [1], and the mortality rate associated with difficult airway is sometimes as high as $30 \%$ [2]. Retaining spontaneous breathing and awake intubation are effective methods to manage patients with suspected difficult airway [3], but awake intubation can lead to intense stress and cardiovascular response. There are many methods of awake intubation. Reasonable sedation and analgesia are the keys to this procedure's success [4]. Sufentanil is a synthetic opioid drug mainly used to activate $\mu$ receptors. It has a strong analgesic effect, little effect on hemodynamics, and can effectively inhibit endotracheal intubation response. At present, sufentanil is the most commonly used analgesic drug in general anesthesia induction and maintenance [5]. However, while sufentanil inhibits analgesia and endotracheal intubation, central respiratory inhibition is also common [6]. Balancing sufentanil analgesia with respiratory depression is a challenge for anesthesiologists.

Sufentanil is associated with an increased risk of hypoxemia and apnea [7], which is particularly undesirable for patients and anesthesiologists. This may due to the $\mu$-selective opioid sufentanil showing high affinity for its binding sites which close vicinity to the respiratory regulating centers in the brainstem. Dezocine is a synthetic compound that functions as an $\mu$ receptor agonistantagonist. Our previous studies have shown that pre-injection of dezocine can effectively inhibit the coughing response to sufentanil during induction [8], which may be related to the antagonism of $\mu$ receptors. Whether dezocine can inhibit the respiratory

Page 2/11 
depression caused by sufentanil by partially antagonizes $\mu$ receptors has not been clinically reported. Dezocine has a strong analgesic effect and can effectively suppress the stress response caused by endotracheal intubation [9]. Therefore, this study aimed to explore the rate of respiratory depression and patient satisfaction.

\section{Methods}

Ethical approval for this study was provided by the Ethical Committee of Anhui Medical University, Hefei, Anhui (approval number:20160104). All patients provided written informed consent. The trial was registered before patient enrollment at clinicaltrials.gov (NCT02673723, Principal investigator: Erwei Gu, Date of registration: February 4, 2016). We conducted the study according to the principles of the Helsinki Declaration and the International Conference on Harmonization guidelines for Good Clinical Practice, at the First Affiliated Hospital of Anhui Medical University.

The study examined 480 adult patients scheduled at five hospitals in China for general anesthesia tracheal intubation between March 2016 and December 2018. Included study participants were aged 18-65 years, with an American Society of Anesthesiologists (ASA) physical status classification of I-II. Exclusion criteria included: severe bradycardia or any type of electrocardiogram conduction block, use of an a agonist or antagonist within two weeks; opioid use within 24 hours; serious heart, liver, kidney, or cerebrovascular disease; allergy to the drugs used in this study; predictably difficult airway; three instances of intubation failure or the patient unable to bear intubation; any respiratory illness; obstacles in language communication; or a person of unsound mind.

Patients were randomly divided into a dezocine group and a saline group. Dezocine was dosed in kilograms of body weight. The specific method of random grouping is as follows: the patients in each center entered the test groups according to the order of enrollment and the random number (scratch card) generated by the statistical software. Randomization results were concealed in opaque envelopes until informed consent had been given. Patients and perioperative period observers were blind to the patient's assigned group.

\section{Anesthesia and research procedure}

Baseline vital signs were recorded immediately before the procedure. All patients received supplemental oxygen intranasally $(6 \mathrm{~L} / \mathrm{min})$ and underwent continuous monitoring of heart rate (three-lead electrocardiography), oxygen saturation (pulse oximetry), blood pressure (automated blood pressure cuff, serial measurements every 3 minutes). The respiratory rate and end-tidal $\mathrm{CO}_{2}$ were also recorded. Dezocine (5 mg/mL; Yangtze River Pharmaceutical, Co., Jiangsu, China) was diluted with normal saline to one $\mathrm{mg} / \mathrm{mL}$ and was administered with one bolus of dezocine $0.05 \mathrm{mg} / \mathrm{kg}$ (D0.05 group), $0.10 \mathrm{mg} / \mathrm{kg}$ (D0.1 group), $0.15 \mathrm{mg} / \mathrm{kg}$ (D0.15 group), or an equal volume of $0.9 \%$ normal saline (saline group) intravenously three to five seconds before anesthesia induction. Sufentanil (Yichang Humanwell Pharmaceutical Co., Hubei, China) was diluted with normal saline from its original concentration of $50 \mu \mathrm{g} / \mathrm{mL}$ to a concentration of $5 \mu \mathrm{g} / \mathrm{mL}$. Two minutes later, all patients received $0.4 \mu \mathrm{g} / \mathrm{kg}$ sufentanil over three seconds. Five minutes after sufentanil injection, the anesthesiologist used a laryngoscope to expose the glottis, and topical anesthesia was performed with two $\mathrm{mL} 2 \%$ lignocaine via the larynx. Two minutes later, the anesthesiologist exposed the glottis for tracheal intubation.

Immediately after injection, an anesthetic registrar recorded the occurrence of cough as 'yes' or 'no'. Depending on the number of coughs observed, the cough severity was graded as mild (one to two), moderate (three to five), or severe (> five). Blood pressure and heart rate (HR) were recorded before sufentanil injection(T0-s), one minute (T1-s), three minutes (T3-s), and five minutes (T5-s) after sufentanil injection. Blood pressure and HR were recorded during intubation (T1), and at one minute (T2) and three minutes (T3) after intubation, and the patient's intubation response were observed in terms of five variables $[10,11]$

a. Ease of intubation: 1 - very easy, 2 - easy, 3 - general, 4 - difficult, 5 - very difficult.

b. Intubation comfort score: 1 - no reaction, 2 - slight grimacing, 3 - heavy grimacing, 4 - verbal objection, and 5 - defensive movement of head or hands.

c. Limb movement: 1 - none, 2 - slight, 3 - moderate, and 4 - severe.

d. Glottis exposure:1- full exposure, 2- partial exposure, and 3 - no exposure.

e. Patient Satisfaction:1- very satisfied, 2-satisfied, 3- no opinion, 4-dissatisfied, -very dissatisfied. 
If patients experienced adverse reactions such as hypertension, hypotension, tachycardia, bradycardia, or respiratory depression during the experiment, we had corresponding unified treatment measures.

The primary outcome of our study was to observe the incidence of respiratory depression. Respiratory depression was considered to be significant when $\mathrm{SpO}_{2}$ was $90 \%$, end-tidal $\mathrm{CO}_{2}$ was $>50 \mathrm{mmHg}$ at any time, respiratory rate was $<6$ breaths/minute, or when airway obstruction with the cessation of gas exchange was observed at any time (noted by an absent end-tidal $\mathrm{CO}_{2}$ waveform).

Secondary outcomes included the success rate of intubation, ease of intubation, intubation comfort score, sore throat, hoarseness, lethargy, limb movement, glottis exposing, and the satisfaction of patients during intubation. Hemodynamic changes were recorded after sufentanil injection and awake intubation. The patients' memories, throat pain, and hoarseness were followed up 24 hours after the operation.

\section{Statistical analyses:}

According to the results of our preliminary experiment, this study required at least 88 patients per group to attain appropriate power ( $a=0.05$ [two-tailed]; $\beta=0.2$ ). The sample size was increased to 120 patients per group to account for any dropouts. Data are expressed as mean \pm standard deviation (SD) or as the number or percentage of patients. Patient characteristics and the hemodynamic variables between the groups were compared using unpaired two-tailed $t$-tests. The incidence and severity of cough, gender proportions, and ASA class were assessed using Chi-squared tests and Fisher's exact test with Bonferroni correction. $P<0.05$ was defined significance. A Bonferroni correction would be used if the difference between groups was $P<0.05$. $P<0.0083$ was used to define significance to reduce the risk of type I error due to multiple analyses or for subgroup interactions. All analyses were performed using SPSS 16.0 .

\section{Results}

From March 2016 to December 2018, 480 patients were screened. Of these, 31 patients had their operations canceled, 25 patients declined participation, and the anesthetic plan of 21 patients was altered. A total of 403 patients (ASA physical status I or II) were enrolled in the study. Five patients failed to receive awake intubation (three cases in the saline group and two cases in the D0.05 group). The final analysis consisted of 403 patients (D0.05 group, $n=101 ;$ D 0.1 group, $n=100 ;$ D0.15 group, $n=101$; saline group, $\mathrm{n}=101)$. Patient demographic characteristics were similar across the four groups (Table1).

\section{Primary outcome}

The intubation variables of 403 participants assigned to the dezocine or saline groups were shown in Table 2. Respiratory depression was statistically different between the four groups $(P<0.05)$. The incidence of respiratory depression in the saline group was $22.8 \%$, while that in the D0.05 group was $19 \%$, the D0.10 group was $3 \%$ and the D 0.15 group was $2 \%$. Fisher's exact test $\left(2{ }^{\star} C\right)$ showed that there was a statistically significant difference among the four groups $(P<0.001)$. Bonferroni correction was used to adjust the level of a for $\mathrm{p} 2 \mathrm{p}$ comparison. There was no difference in the effect of normal saline and $0.05 \mathrm{mg} / \mathrm{kg}$ dezocine on respiratory depression $(P=0.603)$. The results showed that there were significant differences between $0.10 \mathrm{mg} / \mathrm{kg}$ dezocine and 0.15 $\mathrm{mg} / \mathrm{kg}$ dezocine in respiratory inhibition compared with saline (all $P<0.0083$ ).

\section{Secondary outcomes}

Intubation-related data, including sore throat, hoarseness, lethargy, and success awake intubation were similar across the four groups (all $P>0.05)$. The cough was statistically different between the four groups $(P<0.05)$. The incidence of cough was $37.6 \%$ in the saline group, $5 \%$ in the D0.05 group, and 0 in the D0.10, and D0.15 groups.

As shown in Table 3, there was no difference between the four groups except for patient satisfaction. In the saline group, five (5\%) patients were very dissatisfied during awake intubation, while there were no (0\%) very dissatisfied patients in the D0.05 group, D0.1group, and D0.15 group. Notably, the ease of intubation was not significantly different between the four groups, and neither was tolerance to intubation, bodily-kinesthetic, or glottis exposure $(P>0.05)$.

The hemodynamic changes before and after sufentanil injection observed between the four groups were shown in Table 4. SBP was not significantly different between the four groups before or after sufentanil injection, nor was DBP $(P>0.05)$. Notably, there was a 
significant difference in HR $(P<0.05)$. The hemodynamic changes before and after intubation observed between the four groups were shown in Table 5. The SBP and DBP were also not significantly different between the four groups before or after intubation $(P>$ $0.05)$, but there was a significant difference in $\mathrm{HR}(P<0.05)$.

\section{Discussion}

Sufentanil intravenously increased opioid-induced cough and respiratory depression [8]. Our study found that dezocine combined with sufentanil for awake intubation completely suppressed the incidence of cough caused by sufentanil, This provided better awake intubation conditions, which was in agreement with the prior study [12]. Meanwhile, dezocine can inhibit the respiratory depression caused by sufentanil in awake intubation, The incidences of absent end-tidal $\mathrm{CO}_{2}, \mathrm{SpO}_{2}<90 \%$, and $\mathrm{RR}<6$ breaths/min were significantly lower in Group D0.10 and Group D0.15 than in the saline group $(p<0.05)$. There was a dose-response relationship in terms of respiratory depression in the dezocine groups $(p<0.05)$. The incidence of respiratory depression was decreased when the dose of dezocine was increased. No statistically significant respiratory depression differences were noted between Group D0.10 and Group D0.15. Five patients developed respiratory depression in Group D0.10 and Group D0.15 $\left(\mathrm{SPO}_{2}<90 \%\right)$, but none of them required jaw support or emergency tracheal intubation. Five patients were still responsive to command and able to carry out instructions. The patient's hypoxemia was quickly relieved simply by giving the patient verbal encouragement to breathe.

Awake intubation is the standard of care for the management of the anticipated difficult airway in adult patients [13, 14]. Awake intubation can improve the survival rate and reduce the death rate of patients with difficult airways. However, the disadvantages of awake intubation include poor patient tolerance, patient unwillingness to cooperate, and dramatic hemodynamic fluctuations. Optimal conditions for awake intubation include that a patient should be comfortable, cooperative, free of oropharyngeal blood and secretions, and able to maintain their airway with spontaneous ventilation [15]. An ideal drug should be short-acting, easily titratable, provide the required amount of sedation, and have little suppression of spontaneous ventilation are chosen [16]. In the last three decades, several drugs have been utilized such as midazolam, sufentanil, remifentanil, and dexmedetomidine [17-19]. When the sedative and analgesic drugs were selected for awake intubation, the adverse event most concerned by the anesthetists was respiratory depression. Opioids are strong analgesics with some hypnotic effect and can help attenuate the cough and hemodynamic changes during awake intubation. Opioids have been used as adjuncts to sedation for awake intubation [20]. Nevertheless, opioids with large doses for sedation can be associated with significant hypoxemia $\left(\mathrm{SpO}_{2}<90 \%\right)$, apnea, and hemodynamic fluctuation [21].

Sufentanil is one of the strongest opioids to inhibition of tracheal intubation response. Studies have shown that an induced dose of $0.3 \mathrm{ug} / \mathrm{kg}$ causes hypotension [22]. In this study, we found that blood pressure and heart rate did not change more than $20 \%$ of the baseline value after sufentanil injection in the four groups $(P>0.05)$. It is suggested that $0.4 \mathrm{ug} / \mathrm{kg}$ sufentanil is safe for awake intubation. Perfect tracheal epithelial anaesthesia is the key to inhibit awake tracheal intubation response, In our study,though it was found that the blood pressure and heart rate of patients after intubation were higher than before intubation, while the change value did not exceed $20 \%$ of the basic value.

Studies have shown that sufentanil is not an ideal drug for awake intubation alone [23]. In our study, the incidence of respiratory depression during awake intubation was $22.8 \%$ in the saline group, which was in agreement with previous studies [23, 24]. While that in the D0.05 group was 19\%, the D 0.10 group was $3 \%$ and the D 0.15 group was $2 \%$. Our study found that dezocine can reduce the incidence of respiratory depression caused by sufentanil in awake intubation. Simultaneously, that dezocine combined with sufentanil could also provide a suitable depth of sedation and good depth of sedation during awake intubation increases patient satisfaction.

Opioids induce analgesia and respiratory depression via stimulation of $\mu$-opioid receptors (MORs). MORs are found in abundance in respiratory control centers in pons and brainstem, such as the pre-Bötzinger complex, a respiratory rhythm generating area in the pons $[25,26]$. One approach to the development of opioid analgesic drugs with lower risk factors for respiratory depression has been the development of partial agonists at the MOR, such as dezocine [27]. Dezocine is a synthetic compound that functions as an $\mu$ receptor agonist-antagonist. Dezocine has a strong analgesic effect and can effectively inhibit the stress response caused by endotracheal intubation. The therapeutic dose of dezocine does not produce significant respiratory inhibition [28]. Does this separation of analgesia and respiratory depression mean that the subtype of MOR exists? The exact mechanism needs further study. 
There were several limitations in this study. First, all patients in our study were not difficult airways, We did not explore the effect of dezocine in combination with sufentanil on awake intubation in patients with a difficult airway. Second, the satisfaction of patients in the saline group was lower than that in the dezocine group, which might be related to the sedative and analgesic effects of dezocine, which warrants further studies.

\section{Conclusion}

In conclusion, our results suggest that dezocine may effectively prevent the occurrence of sufentanil-induced irritating respiratory depression during awake intubation. Therefore, Sufentanil combined with dezocine could be a clinically effective method for awake intubation.

\section{Abbreviations}

ASA: American Society of Anesthesiologists; HR: Heart rate; SBP: Systolic blood pressure; DBP: Diastolic blood pressure; MBP: Mean blood pressure; SD: Standard deviation; MOR $\ \mu$-opioid receptor

\section{Declarations}

\section{Ethics approval and consent to participate}

Ethical approval for this study was provided by the Ethical Committee of Anhui Medical University, Hefei, Anhui (approval number:20160104). All patients provided written informed consent. The trial was registered prior to patient enrollment at clinicaltrials.gov(NCT02673723, Principal investigator: Erwei Gu, Date of registration: February 4, 2016). We conducted the study according to the principles of the Helsinki Declaration and the International Conference on Harmonization guidelines for Good Clinical Practice, at the First Affiliated Hospital of Anhui Medical University.

The findings of the study were reported according to the CONSORT guidelines.

\section{Consent for publication}

Not Applicable.

\section{Availability of data and materials}

The data that supports the findings of this study are available on request from the corresponding author. The data are not publicly available due to privacy or ethical restrictions.

\section{Competing interests}

The authors confirm that this article content has no conflicts of interest.

\section{Funding}

This work was supported by grants from the National Natural Science Foundation of China $(81870841,81571039)$.

\section{Authors' contributions}

$X P$ and $H Y Z$ made substantive intellectual contributions to the interpretation of data and draft of the manuscript. $R L, S J X, X J$, and Q Z assisted in data collection, analysis, and interpretation. GH X, XQ C, EW G, and XS L were involved in the design of this study, data collection, analysis, and interpretation of data, drafting and revising the manuscript.

The authors had read and approved the final manuscript.

\section{Acknowledgements}

The authors appreciate the 480 research subjects for their devotion and cooperation. 


\section{References}

1. Shiga T, Wajima Z, Inoue T, Sakamoto A. Predicting difficult intubation in apparently normal patients: a meta-analysis of bedside screening test performance. Anesthesiology. 2005;103(2):429-437.

2. Schmitt H, Buchfelder M, Radespiel-Tröger M, Fahlbusch R. Difficult intubation in acromegalic patients: incidence and predictability. Anesthesiology. 2000;93(1):110-114.

3. Rosenstock CV, Thøgersen B, Afshari A, Christensen AL, Eriksen C, Gätke MR. Awake fiberoptic or awake video laryngoscopic tracheal intubation in patients with anticipated difficult airway management: a randomized clinical trial. Anesthesiology. 2012;116(6):1210-1216.

4. Cattano D, Lam NC, Ferrario L, et al. Dexmedetomidine versus Remifentanil for Sedation during Awake Fiberoptic Intubation. Anesthesiol Res Pract. 2012;2012:753107.

5. Thomson IR, Henderson BT, Singh K, Hudson RJ. Concentration-response relationships for fentanyl and sufentanil in patients undergoing coronary artery bypass grafting. Anesthesiology. 1998;89(4):852-861.

6. Thompson CA. Prevention of respiratory depression becomes safety foundation's new goal. Am J Health Syst Pharm. 2007;64(8):798-799.

7. Miller RD, Cohen NH, Eriksson LI, Fleisher LA, Wiener-Kronish JP, Cohen NH. Miller's anesthesia. $8^{\text {th }}$ Philadelphia: Elsevier Saunders; 2015.

8. Liu XS, Xu GH, Shen QY, et al. Dezocine prevents sufentanil-induced cough during general anesthesia induction: A randomized controlled trial. Pharmacol Rep. 2015;67(1):52-55.

9. Lv Z, Fang J, Zhu J, et al. Intravenous dezocine pretreatment reduces the incidence and intensity of myoclonus induced by etomidate. J Anesth. 2014;28(6):944-947.

10. Chernik DA, Gillings D, Laine $H$, et al. Validity and reliability of the Observer's Assessment of Alertness/Sedation Scale: study with intravenous midazolam. J Clin Psychopharmacol. 1990;10(4):244-251.

11. Ambuel B, Hamlett KW, Marx CM, Blumer JL. Assessing distress in pediatric intensive care environments: the COMFORT scale. J Pediatr Psychol. 1992;17(1):95-109.

12. Law JA, Morris IR, Brousseau PA, de la Ronde S, Milne AD. The incidence, success rate, and complications of awake tracheal intubation in 1,554 patients over 12 years: an historical cohort study. Can J Anaesth. 2015;62(7):736-744.

13. Apfelbaum JL, Hagberg CA, Caplan RA, et al. Practice guidelines for management of the difficult airway: an updated report by the American Society of Anesthesiologists Task Force on Management of the Difficult Airway. Anesthesiology. 2013;118(2):251270.

14. Benumof JL. Management of the difficult adult airway. With special emphasis on awake tracheal intubation [published correction appears in Anesthesiology 1993 Jan;78(1):224]. Anesthesiology. 1991;75(6):1087-1110.

15. Dang BW, Zhang J. Safety and efficacy of argon plasma coagulation for resection of lipomas and hamartomas in large airways. Asian Pac J Cancer Prev. 2011;12(2):477-480.

16. Cattano D, Lam NC, Ferrario L, et al. Dexmedetomidine versus Remifentanil for Sedation during Awake Fiberoptic Intubation. Anesthesiol Res Pract. 2012;2012:753107.

17. Rai MR, Parry TM, Dombrovskis A, Warner OJ. Remifentanil target-controlled infusion vs propofol target-controlled infusion for conscious sedation for awake fibreoptic intubation: a double-blinded randomized controlled trial. Br J Anaesth. 2008;100(1):125130.

18. Lallo A, Billard V, Bourgain JL. A comparison of propofol and remifentanil target-controlled infusions to facilitate fiberoptic nasotracheal intubation. Anesth Analg. 2009;108(3):852-857.

19. Tsai CJ, Chu KS, Chen TI, Lu DV, Wang HM, Lu IC. A comparison of the effectiveness of dexmedetomidine versus propofol targetcontrolled infusion for sedation during fibreoptic nasotracheal intubation. Anaesthesia.2010;65(3): 254-259.

20. Vennila R, Hall A, Ali M, Bhuiyan N, Pirotta D, Raw DA. Remifentanil as single agent to facilitate awake fibreoptic intubation in the absence of premedication. Anaesthesia. 2011;66(5):368-372.

21. Bailey PL, Pace NL, Ashburn MA, Moll JW, East KA, Stanley TH. Frequent hypoxemia and apnea after sedation with midazolam and fentanyl. Anesthesiology. 1990;73(5):826-830. 
22. Jor O, Maca J, Koutna J, et al. Hypotension after induction of general anesthesia: occurrence, risk factors, and therapy. A prospective multicentre observational study. J Anesth. 2018;32(5):673-680.

23. Mondal S, Ghosh S, Bhattacharya S, Choudhury B, Mallick S, Prasad A. Comparison between dexmedetomidine and fentanyl on intubation conditions during awake fiberoptic bronchoscopy: A randomized double-blind prospective study. J Anaesthesiol Clin Pharmacol. 2015;31(2):212-216.

24. Wang YH, Chai JR, Xu XJ, et al. Pharmacological Characterization of Dezocine, a Potent Analgesic Acting as a $\mathrm{k}$ Partial Agonist and $\mu$ Partial Agonist. Sci Rep. 2018;8(1):14087. Published 2018 Sep 20.

25. Boom M, Niesters M, Sarton E, Aarts L, Smith TW, Dahan A. Non-analgesic effects of opioids: opioid-induced respiratory depression. Curr Pharm Des. 2012;18(37):5994-6004.

26. Montandon G, Qin W, Liu H, Ren J, Greer JJ, Horner RL. PreBotzinger complex neurokinin-1 receptor-expressing neurons mediate opioid-induced respiratory depression. J Neurosci. 2011;31(4):1292-1301.

27. Liu R, Huang XP, Yeliseev A, Xi J, Roth BL. Novel molecular targets of dezocine and their clinical implications. Anesthesiology. 2014;120(3):714-723.

28. Shen SL, Xie YH, Wang WY, Hu SF, Zhang YL. Comparison of dexmedetomidine and sufentanil for conscious sedation in patients undergoing awake fibreoptic nasotracheal intubation: a prospective, randomised and controlled clinical trial. Clin Respir J. 2014;8(1):100-107.

\section{Tables}

Table 1 Characteristics for $\mathbf{4 0 3}$ participants allocated to intra-operative dezocine or saline.

\begin{tabular}{|llllll|}
\hline & Saline $(\mathrm{n}=101)$ & $\mathrm{D} 0.05(\mathrm{n}=101)$ & $\mathrm{D} 0.1(\mathrm{n}=100)$ & $\mathrm{D} 0.15(\mathrm{n}=101)$ & $P$ value \\
\hline Age $(\mathrm{y})$ & $43.80 \pm 10.15$ & $42.68 \pm 11.90$ & $44.81 \pm 10.53$ & $41.84 \pm 11.53$ & 0.259 \\
\hline Height $(\mathrm{cm})$ & $163.42 \pm 7.14$ & $161.48 \pm 1.19$ & $162.32 \pm 6.66$ & $162.42 \pm 6.23$ & 0.213 \\
\hline Weight $(\mathrm{kg})$ & $59.78 \pm 7.67$ & $58.39 \pm 8.00$ & $59.70 \pm 8.06$ & $59.07 \pm 7.25$ & 0.550 \\
\hline $\begin{array}{l}\text { Gender } \\
\text { (Female/Male) }\end{array}$ & $67 / 34$ & $73 / 27$ & $72 / 29$ & $78 / 23$ & 0.384 \\
\hline
\end{tabular}

Data are expressed as mean \pm standard deviation $(\mathrm{SD})$ or as the number or percentage of patients.

Patient characteristics between the groups were compared using unpaired two-tailed $t$ tests.

Table2 Intra-operative variables for 403 participants allocated to intra-operative dezocine or saline.

\begin{tabular}{|llllll|}
\hline & Saline (n=101) & D0.05 (n=101) & $\begin{array}{l}\text { D0.1 } \\
(n=100)\end{array}$ & $\begin{array}{l}\text { D0.15 } \\
(n=101)\end{array}$ & $P$ value \\
\hline Cough (no/yes) & & & $101 / 0$ & $101 / 0$ & $<0.001$ \\
\hline Sore throat (no/yes) & $63 / 38$ & $95 / 5$ & $85 / 16$ & $86 / 15$ & 0.881 \\
\hline Hoarseness (no/yes) & $81 / 17$ & $85 / 13$ & $88 / 13$ & $89 / 12$ & 0.911 \\
\hline Lethargy (no/yes) & $83 / 15$ & $85 / 13$ & $88 / 13$ & $93 / 8$ & 0.451 \\
\hline Respiratory depression (no/yes) & $93 / 8$ & $93 / 7$ & $98 / 3$ & $99 / 2$ & $<0.001$ \\
\hline Success conscious intubation (no/yes) & $3 / 98$ & $81 / 19$ & $0 / 101$ & $0 / 101$ & 0.117 \\
\hline
\end{tabular}

During the observation of respiratory depression, dezocine in different concentrations was compared with the saline group.

The incidence of intra-operative variables were assessed using Chi-squared tests and Fisher's exact test with Bonferroni correction. 
$P<0.05$ defined significance.

Table 3 Intubation-related response observation.

\begin{tabular}{|llllll|}
\hline group & $\begin{array}{l}\text { Degree of easy } \\
\text { intubation }(1 / 2 / 3 / 4 / 5)\end{array}$ & $\begin{array}{l}\text { Tolerance to } \\
\text { intubation }(1 / 2 / 3 / 4 / 5)\end{array}$ & $\begin{array}{l}\text { Limb } \\
\text { movement }(1 / 2 / 3 / 4)\end{array}$ & $\begin{array}{l}\text { Glottis } \\
\text { exposing }(1 / 2 / 3)\end{array}$ & $\begin{array}{l}\text { The satisfaction of } \\
\text { patients }(1 / 2 / 3 / 4 / 5)\end{array}$ \\
\hline $\begin{array}{l}\text { Saline } \\
(n=101)\end{array}$ & $38 / 50 / 5 / 3 / 5$ & $81 / 10 / 3 / 1 / 6$ & $93 / 0 / 3 / 5$ & $63 / 35 / 3$ & $10 / 65 / 8 / 13 / 5$ \\
\hline $\begin{array}{l}\text { D0.05 } \\
(n=101)\end{array}$ & $55 / 29 / 8 / 5 / 3$ & $82 / 10 / 3 / 0 / 5$ & $97 / 0 / 0 / 3$ & $70 / 25 / 5$ & $15 / 75 / 7 / 3 / 0$ \\
\hline $\begin{array}{l}\text { D0.10 } \\
(n=100)\end{array}$ & $50 / 38 / 13 / 0 / 0$ & $90 / 8 / 0 / 0 / 3$ & & & $71 / 30 / 0$ \\
\hline $\begin{array}{l}\text { D0.15 } \\
\text { (n=101) }\end{array}$ & $53 / 38 / 10 / 0 / 0$ & $98 / 3 / 0 / 0$ & & $18 / 75 / 5 / 3 / 0$ \\
\hline$P$ & 9.152 & $98 / 0 / 3 / 0$ & $76 / 25 / 0$ & $20 / 78 / 3 / 0 / 0$ \\
\hline
\end{tabular}

The Intubation-related response were assessed using Chi-squared tests and Fisher's exact test with Bonferroni correction.

$P<0.05$ defined significance.

Table 4 The hemodynamic changes before and after sufentanil injection observed between the four groups.

\begin{tabular}{|c|c|c|c|c|c|c|}
\hline & Groups & TO-S & T1-S & T3-S & T5-S & \\
\hline \multirow[t]{4}{*}{ SBP (mmHg) } & Saline & $120.70 \pm 15.09$ & $120.24 \pm 15.91$ & $118.99 \pm 17.41$ & $119.51 \pm 18.31$ & \multirow{4}{*}{$\begin{array}{l}F=1.375 \\
P=0.195\end{array}$} \\
\hline & D0.05 & $124.74 \pm 12.72$ & $125.13 \pm 14.36$ & $122.91 \pm 15.26$ & $123.04 \pm 15.59$ & \\
\hline & D0.10 & $124.67 \pm 11.31$ & $125.07 \pm 17.34$ & $123.75 \pm 14.59$ & $124.40 \pm 17.16$ & \\
\hline & D0.15 & $125.42 \pm 12.87$ & $127.44 \pm 15.51$ & $124.52 \pm 14.93$ & $122.46 \pm 16.38$ & \\
\hline \multirow[t]{4}{*}{$\mathrm{DBP}(\mathrm{mmHg})$} & Saline & $73.43 \pm 11.25$ & $71.88 \pm 10.42$ & $71.67 \pm 10.55$ & $71.36 \pm 11.08$ & \multirow{4}{*}{$\begin{array}{l}\mathrm{F}=1.600 \\
P=0.110\end{array}$} \\
\hline & D0.05 & $74.18 \pm 9.00$ & $74.09 \pm 8.89$ & $72.02 \pm 9.63$ & $72.00 \pm 9.15$ & \\
\hline & D0.10 & $75.25 \pm 7.35$ & $74.59 \pm 8.13$ & $73.96 \pm 9.11$ & $73.37 \pm 10.73$ & \\
\hline & D0.15 & $74.07 \pm 9.19$ & $73.65 \pm 8.49$ & $71.78 \pm 9.64$ & $70.25 \pm 10.39$ & \\
\hline \multirow[t]{4}{*}{ HR (bpm) } & Saline & $77.93 \pm 11.44$ & $77.25 \pm 12.53$ & $74.53 \pm 12.05$ & $73.42 \pm 11.39$ & \multirow{4}{*}{$\begin{array}{l}F=1.958 \\
P=0.041\end{array}$} \\
\hline & D0.05 & $77.80 \pm 13.36$ & $74.71 \pm 12.92$ & $72.74 \pm 13.68$ & $71.63 \pm 13.86$ & \\
\hline & D0.10 & $77.04 \pm 11.88$ & $74.23 \pm 13.08$ & $71.98 \pm 12.54$ & $72.29 \pm 12.07$ & \\
\hline & D0.15 & $76.59 \pm 9.76$ & $72.81 \pm 9.97$ & $70.87 \pm 9.57$ & $70.77 \pm 9.86$ & \\
\hline
\end{tabular}

The hemodynamic variables between the groups were compared using unpaired two-tailed t tests. $\mathrm{P}<0.05$ defined significance.

Table 5 The hemodynamic changes before and after intubation observed between the four groups. 


\begin{tabular}{|c|c|c|c|c|c|c|}
\hline & Groups & T0 & $\mathrm{T} 1$ & T2(1min) & T3(3min) & \\
\hline \multirow[t]{4}{*}{$\mathrm{SBP}(\mathrm{mmHg})$} & Saline & $120.56 \pm 15.14$ & $131.80 \pm 17.14$ & $128.03 \pm 17.20$ & $121.21 \pm 16.70$ & \multirow{4}{*}{$\begin{array}{l}F=0.703 \\
P=0.706\end{array}$} \\
\hline & D0.05 & $124.56 \pm 12.72$ & $132.38 \pm 16.27$ & $129.29 \pm 16.22$ & $123.69 \pm 14.37$ & \\
\hline & D0.10 & $124.70 \pm 11.36$ & $134.54 \pm 17.20$ & $130.54 \pm 17.19$ & $124.16 \pm 15.34$ & \\
\hline & D0.15 & $125.33 \pm 12.91$ & $133.11 \pm 18.13$ & $129.63 \pm 16.56$ & $123.11 \pm 14.89$ & \\
\hline \multirow[t]{4}{*}{$\mathrm{DBP}(\mathrm{mmHg})$} & Saline & $73.27 \pm 11.28$ & $75.70 \pm 10.57$ & $74.07 \pm 10.56$ & $69.90 \pm 10.60$ & \multirow{4}{*}{$\begin{array}{l}F=0.507 \\
P=0.870\end{array}$} \\
\hline & D0.05 & $74.16 \pm 9.08$ & $76.70 \pm 10.42$ & $73.85 \pm 10.49$ & $70.16 \pm 11.16$ & \\
\hline & D0.10 & $75.24 \pm 7.38$ & $79.17 \pm 10.39$ & $76.72 \pm 9.45$ & $72.69 \pm 8.53$ & \\
\hline & D0.15 & $74.01 \pm 9.22$ & $75.84 \pm 11.37$ & $74.01 \pm 10.64$ & $70.51 \pm 9.86$ & \\
\hline \multirow[t]{4}{*}{$\mathrm{HR}(\mathrm{bpm})$} & Saline & $78.05 \pm 11.39$ & $87.97 \pm 14.77$ & $82.59 \pm 12.94$ & $78.51 \pm 11.80$ & \multirow{4}{*}{$\begin{array}{l}F=1.918 \\
P=0.046\end{array}$} \\
\hline & D0.05 & $77.97 \pm 13.53$ & $83.64 \pm 16.26$ & $79.31 \pm 15.82$ & $75.55 \pm 14.77$ & \\
\hline & D0.10 & $77.05 \pm 11.94$ & $83.04 \pm 17.19$ & $79.92 \pm 13.96$ & $76.54 \pm 13.32$ & \\
\hline & D0.15 & $76.64 \pm 9.79$ & $86.24 \pm 15.97$ & $81.45 \pm 13.56$ & $75.51 \pm 10.84$ & \\
\hline
\end{tabular}

The hemodynamic variables between the groups were compared using unpaired two-tailed t tests. $P<0.05$ defined significance.

\section{Figures}

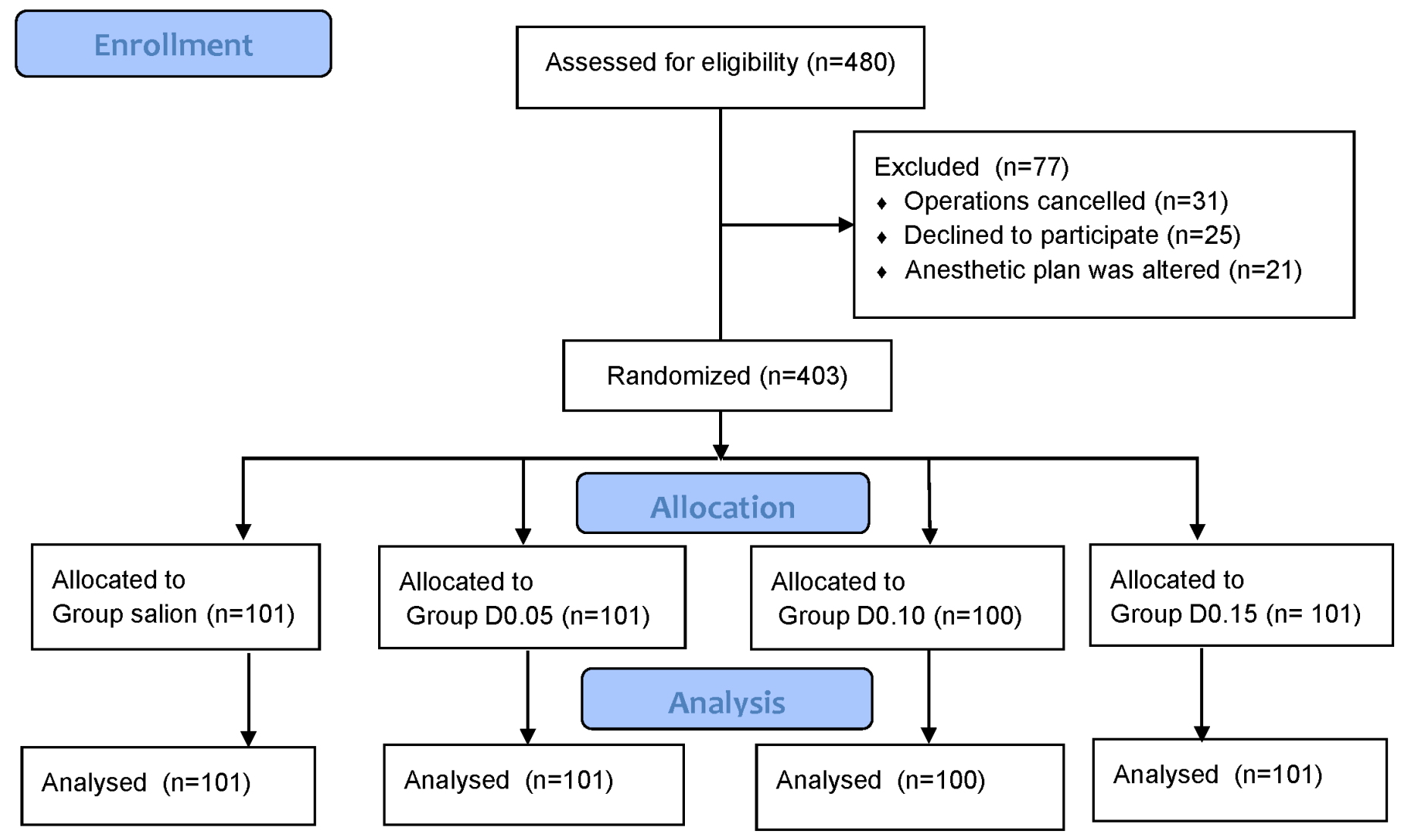

Figure 1

The CONSORT flowchart 


\section{Supplementary Files}

This is a list of supplementary files associated with this preprint. Click to download.

- CONSORT2010Checklist.doc 